ISSN 2079-3871

\title{
Staying in Sync: Keeping Popular Music Pedagogy Relevant to an Evolving Music Industry
}

\author{
Don Lebler
}

Queensland Conservatorium, Griffith University

d.lebler@griffith.edu.au

\section{Donna Weston}

Queensland Conservatorium, Griffith University

d.weston@griffith.edu.au

\begin{abstract}
The Bachelor of Popular Music (BPM) program operates in purpose built facilities on the Gold Coast campus of Griffith University (Queensland, Australia). The degree design replicates how musicians progress outside formal learning contexts in an enhanced higher education environment, including self-directed and collaborative learning, participatory assessment, and critical listening as core activities. Graduates are independent musicians, having studied popular music history and analysis, audio production, songwriting and performance, ensuring competence in a broad range of popular music activities.

While the structure of the degree remains constant, the content and processes remain fluid in response to the rapid changes in the music industry. Reflecting the increasingly artist-driven nature of the industry itself, student consultation has provided the impetus for many of these changes. The primary goal of the program was, and still is, to produce graduates who are multi-skilled and able to engage effectively with the popular music industry, prepared to adapt to the changes that are characteristic of this dynamic field.
\end{abstract}


This paper documents this process of change over a fifteen-year period, showing how pedagogy can respond to continually changing industry demands.

KEYWORDS: popular music learning, popular music pedagogy, participatory assessment, career preparation, entrepreneurship

\section{The context}

The goal of the Bachelor of Popular Music (BPM) program is to produce graduates who are prepared for the diverse activities that constitute contemporary popular music practice. This is achieved through study of popular music history and analysis, audio production, songwriting and performance, and through the adoption of a learning-focused approach that utilizes the diverse abilities of its students. Indeed, the creation of an interdependent, largely self-directed learning community is one of the main contributions this program makes to the development of its students. In this context, it is vital that the program reflects contemporary practices and processes of the music industry as closely as possible. This article provides an account of the modifications to the program that have been enacted since its implementation to ensure its relevance to the musical world in which its graduates will work.

When the design of the BPM program ${ }^{1}$ was developed at the Queensland Conservatorium Griffith University during the mid 1990s, there was little published about how popular musicians learned; where popular music was present in higher education, it was usually in the form of the study of popular music rather than the doing of it. This program was designed to include all three aspects of Popular Music Studies described by Martin Cloonan (2005: 83) as "musical, vocational (including business studies) and theoretical".

The incorporation of jazz into higher music education could have provided one model for possible replication, in which case classical repertoire, techniques and practices would have been replaced by their jazz equivalents, but still within the normal structures of a Bachelor of Music, and using very similar pedagogical processes as used in classical music for some time (Kernfeld 2002). In these instances, performance abilities are usually developed under the direction of one expert teacher who is in control of the curriculum and provides direction and feedback. However, the academic team, charged with creating this program, decided on a different approach. They wanted to utilize the learning characteristics of popular musicians in a formal education environment rather than merely insert popular music into existing pedagogical structures.

The development team included popular musicians who were also trained classical or jazz musicians, and when they reflected on their personal learning experiences, it became clear that they had learned popular music quite differently from the way they had learned other music. For their training in jazz and classical music, they had followed the conventional methods for learning music through the formal study of theory, music history and repertoire, and by developing technical skills using a systematic method under the direction of a teacher, who made most of the significant decisions. Success in exams, auditions and competitions were significant extrinsic motivators. In contrast, they had learned 
popular music with and from their friends, under their own direction, intrinsically motivated, self-monitored, often using recordings of their heroes as texts and recordings of their own work as significant objects of constructive reflection. They assumed that these learning experiences were typical of popular musicians and they were proved correct by subsequent publications about how popular musicians learn (Folkestad 2006; Green 2001, 2006, 2008, 2010; Westerlund 2006) and studies conducted within the program itself (Lebler 2006, 2007a, 2007b, 2008, 2010; Lebler, Burt-Perkins and Carey 2009).

Introduced in 1999, the degree primarily attracts applicants seeking careers as performing artists in the popular music industry. The pedagogical approach assumes a high level of discipline knowledge in the student cohort and the audition process identifies applicants who demonstrate ability in songwriting as well as other aspects of popular music practice, such as performance and creative music technologies. Collaborative learning is an important feature of the program, which includes numerous formal and informal opportunities for collaboration, including between students at different stages of the program and, not infrequently, with collaborators outside the program. The structure of the degree was modified in 2009 to include three possibilities for students to undertake workplace learning courses as part of a University initiative, but otherwise, it has remained substantially the same. Aspects of the pedagogy and curriculum were changed to reflect changes in the music industry, including the formats in which music is distributed and consumed. Processes have also changed in search of efficiencies and, importantly, in response to changing student expectations, particularly in relation to the quality of online enhancements to their learning experience. Changes in the program have been enacted from its beginning in an endeavor to emulate informal popular music practices in a formal environment and stay in sync with a rapidly changing context.

\section{Assessment of creative work}

The major study subject in the BPM program is Popular Music Production, a course undertaken in each of the six semesters of the program. Charting the developments of the complex assessment process of the creative production work in this course provides an illustration of how one aspect of the course has responded to both changes in the industry and in the expectations of students. Developments in the content of the course's text based tasks and aspects of the program other than the major study provide another illustration of adaptation to a changing context. The most substantial changes in the assessment of recorded work took place in the period up to 2009, with changes in the written components taking place more recently. These are described below, to emphasize that all aspects of the course interact to produce useful and contextually relevant learning outcomes.

\section{Recordings}

Students are required to submit recordings of their original work as a substantial component of their major study. At the end of each of the six semesters of the 
program, students submit recordings of their original music, along with a clear statement as to their intentions for the recording, details about the contributions of others who were possibly involved, and their observations on the outcome. They also mark themselves using the same criteria as the assessment panels will use later in the process, importantly acting as their own first markers. Making judgments about the quality of one's own work is quite normal for musicians, and is a necessary aspect of practicing alone, even for musicians in formal training between lessons when the teacher will usually be the dominant provider of feedback. This is even more the case for popular musicians who would usually be working without the guidance of a teacher. They are therefore more reliant on their abilities to make well-founded judgments about their own work, even though the exchange of feedback among band-mates or friendship groups is normal in popular music (Lebler 2008; Lebler et al. 2009). The pedagogical requirement that students assess themselves aligns with informal popular music practice.

In accord with the intention to adopt the norms of the popular music industry whenever possible, for the first couple of semesters recordings were submitted on Digital Audio Tape (DAT) or as Recordable CDs (CDRs). These were the media in most common use at that time for the transfer of master recordings in the local music industry, but by the mid 1990s, CDRs were preferred in the professional recording field. Prior to this, the normal mode of transferring audio in the profession was open reel tape, and this had been the case since the 1950s. While multi track tape machines still dominated in the recording studio, the use of tape for transferring master recordings had begun to decline from the late 1980s when various digital media emerged. Recordable compact cassettes were common in domestic environments but were not of high enough quality to be used to transfer professional recordings. Digital Audio Tape (DAT) was a digital format similar in appearance to the compact cassette but capable of high fidelity recording and reproduction. DATs had become common in the recording industry following their release in the late 1980s, but unreliability in both hardware and the associated tape media resulted in declining use of this format, which is no longer in professional use. In 1999 when the program started, CDRs and DATs were the media used by students to present their recorded works for assessment, reflecting common professional formats of the time.

Students also provided notes (sometimes hand written, at first) about their aims and objectives in their recordings, as well as details of the contributions of all participants. These submissions were assessed by a teacher who awarded marks and provided feedback, and at this stage, there were fewer than twenty students. The enrolment more than doubled in 2000 and all written work was required to be presented as electronic word documents that were submitted by email, In 2001, students were required to use pre-formatted sectioned word documents for their written course work that by semester two of that year were submitted to a digital drop box facility in the course web site rather than by email, while the aspects of the written work that reported on the recordings were submitted in preformatted Excel worksheets, to enable calculations and macros for more complex grading processes. Students were generally experienced with electronic documents and forms, and were comfortable with these changes. Using such 
facilities as the digital drop box foreshadowed more direct interactions with web applications that were to follow.

A trial in 2000 demonstrated that students were able to operate effectively as assessors of the recorded submissions, working individually but as members of panels including students from all year levels of the program under the guidance of a teacher. From 2001, panels consisting of six or seven students and a teacher assessed the recorded creative work submissions of six or seven students, and the marks they produced were the basis for the marks awarded by the course convenor in the formal assessment process.

In the BPM assessment process, two marks (each making up 10\% of the overall grade) are awarded for, respectively, the quality of the submission as a whole and for the quality of the student's self-assessment report. Each recorded track is marked out of $40 \%$ of the overall grade and these marks are averaged across the tracks the student submitted, making a total mark allocation of $60 \%$ for the recorded work. Four criteria are used in assessing individual tracks: how well the track meets the stated intentions, how good the track is overall, how good the submitting student's contribution is, and how significant that contribution is in the final recording. The vast majority of submissions are produced collaboratively, sometimes with fellow students but collaborations with people outside the program are also acceptable. The final $20 \%$ of the grade is awarded for the students' contribution to the assessment process. More information about the development of assessment panels and their contribution to the learning outcomes of the course can be found elsewhere (Lebler 2006, 2007a, 2007b, 2008, 2013).

Although self- and peer assessment are not unusual in popular music, to undertake these activities in a systematic manner is not common in informal contexts. This formal assessment process develops students' ability to consider various aspects of work individually, make judgments based on a common understanding of what constitutes quality, and communicate these judgments in a constructive manner according to guidelines developed by David Boud (1995), and to established Consensus Moderation processes (Sadler 2010). Participation in assessment panels was originally a required activity that did not earn any marks, but in response to students' suggestions, the substantial commitment of the students to the assessment process is now acknowledged with a mark for the quality of students' contributions (making up the final $20 \%$ of the overall grade). While such formal processes are not needed outside formal educational contexts, they develop valuable skills that are applicable in a wide range of contexts including in the popular music industry, particularly the ability to communicate feedback constructively.

Once submitted, the recorded tracks were encoded as MP3 files by members of staff and posted on a network player that was available to students in one oncampus MIDI lab. Mainly, this allowed students to preview the tracks they would assess as members of panels that now conducted this aspect of the assessment. From 2001 onwards, playlists were created that sequenced tracks on the basis of the overall marks they received for each track, so that students and teachers could share with the BPM community an understanding of the standards applied in assessing the quality of a recording. These Hot 100 playlists were available in the program's MIDI lab. More than 200 tracks per semester were being added to this collection by the end of 2003, representing a substantial workload for the staff 
involved, but the development of shared understandings of quality are important for the assessment process and also for effective collaborative work for which sharing standards is an important component.

By 2002, there were more than sixty students and processes had become a little more complex and regulated. DATs were replaced by CDRs that could be played on a domestic CD player. CDRs were rapidly becoming the norm in professional recording for the transfer of master recordings, and therefore this became the appropriate format for a program striving to incorporate industry practices.

From 2005, the Hot 100 playlists, mentioned above, were available online in a bespoke Griffith University application called the Music Repertoire Player, enabling students and teachers to access this music off-campus. This application was designed to create playlists with some associated text within a highly secure online environment, restricting access to students enrolled in particular courses and making it virtually impossible to copy the audio files. However, over 600 tracks were submitted in 2005, so the time needed to encode these tracks and add the necessary text for the Music Repertoire Player was substantial, and therefore fast approaching an unsustainable level. Given the rise in the use of encoded audio files for file sharing and audio streaming on the Internet since the late 1990s, one of the ways the continued use of the Repertoire Player could be made more sustainable was to utilize the students' familiarity with this technology by requiring them to submit their recorded work digitally as well as on CD. As with previous adaptations, this change reflected common practices in the popular music industry, and a program intending to prepare graduates to be functional in this context includes the requirement that students demonstrate an ability to operate effectively in that context.

By semester two, 2008, the same assignment submission interface in the course web site as used for the submission of their written work was employed for the recorded work (in MP3 format). This reflected the common practice of receiving feedback on posted recordings on such sites as MySpace. The latter social media site was founded in 2003 and used extensively by musicians to share their work and receive comments. Some students had embraced MySpace as a means of soliciting feedback not just from their feeds and friends, but also from the wider music community, sometimes even from successful artists who they admired. MySpace (and later Facebook) enabled users to interact within a single web site, uploading text, images, audio and video, as well as inviting dialogue with others. This had become an expectation of students when interacting with the Internet, and the BPM program responded. While initial judgments about the quality of the recordings were made using MP3 files, assessment panel meetings take place in the BPM recording studio control rooms, so final judgments about audio quality are made after listening to the full bandwidth CDs through reference standard monitors.

In 2009, the Bachelor of Popular Music Assessment Tool (BoPMAT) was developed, developed specifically to accommodate the complex assessment process used in the major study. This application enabled students to upload their tracks and the associated written work in a single integrated application, with the ability to continue editing their contributions until the assessment items are due. There is a dedicated section for work in progress, where tracks can be uploaded along with details on what the work is intended to be. Feedback on specific 
aspects of the work can be requested and all members of the BPM community have access to this area of the site for the duration of the semester and are able to contribute feedback.

At the end of the semester, submissions are finalized and the application provides provisional allocations of recorded submissions and assessors to panels, following protocols dealing with the students' year level and gender, and avoiding that students assess the work they have also submitted. This was previously a time-consuming process that was undertaken by the convenor of the course. All panel members then interact with the application to listen to the music and read all of the associated written work including the self-assessment. Participants can access context-specific marking guides whenever they provide feedback and assessment, which the BoPMAT collates at the end of the process. Students access their feedback and marks through the BoPMAT once the responsible academic authorizes their publication (see Lebler 2015).

As with the preceding technological innovations, the BoPMAT was designed to meet the expectations of students, which are increasingly being influenced by rapidly developing digital communication technologies, particularly social media. While such development continues, to date the application is able to meet the needs for which it was designed, and has a structure that should enable future adaptation when needed. The assessment aspects of the pedagogy and processes adopted in the major study are functioning well, but further opportunities for improvement in other aspects of the program became evident and these changes are discussed next.

\section{Program changes}

In accordance with Griffith University's academic plan, annual reviews of programs are conducted to ensure their sustained performance and to initiate improvements where necessary. In the case of a program such as the BPM, in which graduate outcomes are dependent on a dynamic and arguably volatile music industry, the relevance of the degree to that industry is crucial. To this end, three important changes were made to the program in 2009 following the annual Plan-Implement-Review-Improve (PIRI) model. This was the first of two major changes to the program. Two areas were identified as in need of review to keep abreast of industry changes: the initiation of genuine engagement with live performance practice early in the program, and the introduction of work integrated learning opportunities (industry internships) in the latter stages of the program.

These first, significant changes to the BPM content and structure were made in the context of significant changes to the music industry. When Radiohead selfreleased their 2007 album In Rainbows independently online, many saw this as an irrevocable end to the control of the major labels. Further, a decline in CD sales from the turn of the century had prompted much debate over the role of piracy and $\mathrm{P} 2 \mathrm{P}$ sharing in that decline, resulting in legal action from major record labels in an attempt to stem what they saw as a controllable, and temporary, anomaly. However, according to Marshall (2013), with the introduction of streamed music services such as Spotify, it seems that revenue from CD sales is 
unlikely to rise again, and may settle into a stable pattern. Record labels have responded to this change, and one such response is the "360 deal" which sees record companies enter deals with artist by which they profit from other, ancillary income streams such as merchandise and live performances (Karubian 2009; Marshall 2013). Significantly, Marshall (ibid.: 83) shows that the major labels now refer to themselves as music companies rather than record labels. These "360", or "multi-rights" deals are not restricted to labels. For example, global company Live Nation Entertainment, formed in 2009 from a merger of Live Nation and Ticketmaster, has made high profile deals with artists, indicating a significant shift in focus within the music industry towards live performance. In 2008, at a Goldman Sachs conference in Las Vegas, Live Nation made a presentation in which they showed their outlook for the music industry: "in it, rather than the record industry being at the centre of the music industry, live music [...] will now be the core" (Marshall 2013: 81). Simon Frith (2007: 3) supports this in his article, "Live Music Matters", in which he describes a boom in the live music sector. He attributes this in part to the investment of international entertainment companies and to the rise in popularity of the music festival. Holt (2010) notes that during the 1980s an artist might earn the same for a concert ticket as they would for the sale of an album; in 2010, one concert ticket could be worth the equivalent of up to ten albums. Clearly, industry revenue streams had undergone significant transformation.

With these shifts in the industry in mind, a new course was introduced into the degree, Live Performance Project. This course was designed to provide students with opportunities to learn about facets of live music performance and production, covering essential skillsets such as performance, stagecraft, management, and live sound. The course consists of lectures, workshops and peer-assessed live performances. The planning of performances is designed to replicate industry equivalents, students working in teams with allocation of workload to branding of the act, marketing of the performance, negotiation of contracts, and lighting and sound. Within one year of the introduction of this course, a distinct change in the student culture was observable, with students actively seeking, and self-organizing, on campus performances resulting in the need to purchase portable PA systems to support this. Within two years, in response to the visibility of a performance culture on campus, demand for student performances from various departments of the University increased markedly, to the extent that the BPM administration was able to demand payment for all student performances by 2011. The increased viability of student acts also translated into greater demand for performers outside of the University, with the BPM providing artists for a range of local music venues and festivals on a regular basis.

Central to the structure of the BPM is the goal of producing graduates who are multi-skilled and able to engage with the popular music industry in the flexible and multifaceted modes demanded of its contemporaneous context. While originally, the principle graduate outcome target of the BPM was a successful portfolio career with a focus on song writing and performance, through successive reviews, analysis of graduate data and alumni feedback, it became clear that while this was still true for many graduates, a significant number had gained 
employment in other areas of the industry such as recording studios and music management.

In response to this data, three Music Industry Internship courses were offered as elective choices in semesters 4, 5 and 6 in place of courses which were deemed to be not as integral to the overall program structure as other courses and whose absence would not hinder normal progression through the BPM program; on the contrary, a student's progression could be advanced. For example, a student who did not feel their career ambitions would benefit from tuition in more advanced audio production techniques could choose an internship project specific to their needs. These changes therefore allowed students to tailor the second half of the program to a specific desired outcome. In 2014, over forty industry-internship partners are available to students, ranging from recording studios, festival organizers, venues, government, schools, live sound suppliers and music management companies, to independent arts organizations. As Watson and Forrest (2012) note, musical skills must now be matched by business skills to ensure professional viability. They describe how "performing musicians now recognize the need to be entrepreneurial in their promotion and associated businesses" (ibid: 103). Internships are one important way in which this can be achieved.

\section{1: Major program review}

In addition to annual program improvement plans, an intensive full program review is conducted every five years; the last such review of the BPM was in 2011. In an approach that was entirely in keeping with the focus of the BPM on industry connections, extensive feedback was sought from the student and alumni cohort that included focus groups, social media surveys, and online discussion groups. Primarily, information was sought about how graduates had transitioned to the working environment and the degree to which current students and alumni felt the program prepared them for employment in the music industry. While the response to the recent introduction of a performance class was overwhelmingly positive, the dominant view of current students was that more emphasis was needed on Music Industry preparation and readiness, and that this could occur in the first year Performance Project course, in Music Industry Studies in third year and in tutorials connected to the Major Study Classes in second year. The growing literature on Arts Entrepreneurship and Higher Education (see for example Bennett 2007, 2008, 2009; Bridgstock 2013, 2014) indicates that more attention should be paid to career preparation for many creative and performing arts graduates. The dominant view of BPM alumni was that the program had not prepared them well enough for the music industry, and that more emphasis was required on marketing, promotion and business skills. They also thought that the information they received in the Music Industry Studies course could be made more relevant to their ambitions in the music industry, such as more practical applications of industry knowledge. Students also wanted the flexibility to stream their studies (specialization).

As a result of this feedback, in conjunction with more traditional review processes such as staff consultation and benchmarking, a number of 
recommendations and subsequent changes were made. Firstly, free electives were offered in semesters three, five and six as alternatives to the Music Industry Internships, with the choice between a designated BPM course, an internship (tailored to a student's career pathway) or a cross-course elective. Electives could be chosen from any school within the University subject to the approval of the program convenor. The ability to enrol in these courses gave students greater opportunities for specialization for example in the areas of secondary music education, business, marketing, or multimedia, allowing students to target potential career pathways, and support portfolio careers.

Students felt that learning relevant music industry information and developing associated skills came too late in the degree - in their final semester - which did not allow them time to capitalize on these skills while still developing their repertoire and profiles. Some tuition in the essentials of live performance was offered in year one as the result of previous changes, however these pertained mainly to licensing, copyright and live contracts. As a result, tutorials attached to the second year Major Study were dedicated to the development of early career skills relevant to employment in the music industry. These included artist promotion, online presence, launching an EP, touring, self-management and working with the media. Research supports the need for music graduates to be able to function equally in a business sense and to be able to source and secure commercial opportunities (Bennett 2007; Bridgstock 2013). This was now addressed in the BPM with a logical progression of course content now in place to cover all aspects relevant to industry engagement by the end of second year. Combined with an increased focus on song writing, stagecraft and promotion, by 2013 the success of these changes was evidenced by a percentage of around 15\% of current students successfully releasing EPs and touring, which was non-existent in 2009.

The emphasis on practical music industry tuition in first and second year opened an opportunity for revision of the third year music industry studies course, the content of which students had indicated they thought could be more relevant. In the focus groups and online discussion, students had argued that this course did not keep abreast of rapid changes in a "hybrid media economy" (Holt 2010: 246) and how to navigate them. In response to this feedback, the content of this course was changed from a practical to a more theoretical approach. While still covering advanced industry related practical skills, such as business management and taxation (for example), the course now focuses on the impact on the music industry of issues in digitization and copyright management, such as piracy, P2P sharing, and streaming.

\section{Engaging with industry}

The changes that came out of the various major and minor reviews of program between 2009 and 2012 resulted in a shift of focus in the BPM from a somewhat insular popular music performance and production oriented degree, to one that is actively engaged in the contemporary music industry. While changes to the program (such as increased focus on live performance, as well as music industry styled self-promotion and management) had assisted students in their ambitions to 
pursue careers as performing artists, there was still a need for the BPM to engage even more directly with the music industry. This was approached through the initiation of an entrepreneurial focused student project in 2012, called Seed, a pioneering, enterprising initiative designed to drive strategic business and student outcomes. It was born from collaboration with the Conservatorium's host University's commercialization branch.

The Seed project draws directly from the student-led assessment processes described in the first section of this article. Each year, the top fifteen to twenty tracks from the annualized Hot 100 are selected for the opportunity for inclusion on a compilation album. Artists of these tracks are invited to submit an Electronic Press Kit (EPK) and business plan if they wish to have their tracks included. Tracks are selected based on the criteria of the artist having a strong online presence, a portfolio of at least thirty minutes of original songs that are performance ready, and a clear business strategy.

The album is promoted and sold online through major online digital stores including iTunes, with students retaining full control of IP, and benefitting financially from any sales. Control of IP has been the right of students since the inception of the BPM, according to conditions that were negotiated through the University's commercialization department. Seed artists are also exposed to industry through an organized concert series at a major venue, individual radio and print media exposure, industry networking sessions, industry mentoring, and opportunities for professional music videos. The Seed project builds on the degree structure and its commitment to the graduation of successful fully independent musicians through its nurturing of entrepreneurialism. By the time they graduate, students involved in the Seed project have sold their own songs, have performed in a professional setting, collaborated with their peers, promoted themselves, created and exploited industry connections and learned how to navigate and succeed in a music industry which is increasingly dominated by independent artists. Seed also aligns with other strands of the BPM through engagement of student interns for live sound reinforcement working with industry professionals. It reflects the music industry in its interdisciplinarity through its engagement with visual arts students for professional photography, CD artwork, promotional material and video as well as business and marketing interns. This is supported in research such as that of Bridgstock (2013: 125), who argues that "the artist who is engaging in the protean career pattern should possess well developed arts entrepreneurship skills, as well as highly developed skills associated with arts practice, that is, creation or making of work". Seed provides students with such entrepreneurial skills. Referring to research undertaken by the UK Department for Culture, Media and Sport, Bennett argues that what the industry needs is "creative and entrepreneurial talents who have also had the chance to develop real-world awareness, commercial know-how and know-who" (2009: 323), and this is exactly what Seed is responding to.

\section{Consolidation}

Recently, further changes were made to the BoPMAT assessment tool, in terms of a refocus of content to reflect industry dynamics, and an introduction of the Seed 
project as incentive for the highest achievers. As a result, the BPM had reached equilibrium, by 2013, requiring only minor adjustments to complement these changes. Entrepreneurship through industry preparation has thereby been "woven into the fabric of the disciplinary curriculum" (Bridgstock 2013: 135). First, the introduction of live performance to the Audio Production courses in third year. As Holt (2010: 248) argues, due to the "splintered economies" that have resulted from the rise of digital media, "live experience and particularly live music have gained greater cultural value in contemporary culture". This change was introduced for two reasons: on the one hand, as a direct response to online presence through outlets, such as YouTube and social networking music sites, where live studio-performance is increasingly being used as a promotional tool; on the other hand, to cater for those students who by their third year expressed little interest in active engagement in recording and production but who nonetheless sought to benefit from the studio experience as performers. In both scenarios, those being recorded and those doing the recording benefit from a deeper understanding of the role of the producer.

The second change occurred in 2014, when project weeks were introduced each semester during which instead of scheduled lectures, master classes, workshops and advisory sessions are conducted by external industry professionals across a range of practices including song writing, audio engineering and production, management, and marketing, capitalizing and building on industry connections. Building on the live performance refocus, stagecraft tutorials were introduced across second and third year, culminating in a graduate industry showcase at the end of third year.

Finally, moving toward internationalization of the program content, six annual competitive scholarships were introduced in 2014, funded by the Queensland Conservatorium, and headed by a sessional lecture with strong links in the USA. Successful applicants first attend the Taxi Music Road Rally in Los Angeles - a music conference that not only highlights the importance of music licensing and publishing in the current music industry but that also gives students the opportunity to actively promote their music to industry professionals. This is followed by five days in Nashville, engaging in co-writing sessions with Nashville composers, open-mic nights, and culminating in a day of recording with Nashville-based producers. These scholarships offer tremendous opportunities not only for the development of musical skills through interaction with internationally successful artists and producers, but also for international networking possibilities.

\section{Conclusion}

Creative practice is central to a program such as the BPM, and the development of pedagogical practices, content and assessment related to creative output is central to the success of both the program and its graduates. This paper shows how changes in technology, student expectations, and increased understanding of the ways in which popular musicians learn influenced the assessment related to the Major Study. Furthermore, changes in the music industry were responded to by continually adapting both the program content and its assessment methods. As Holt (2010) notes, live music has become a major domain and structuring force in 
the economy of music; the main source of income for artists now is generally concerts rather than recordings. Most of the major changes to the BPM were a response to this shift, specifically the focus on live performance, industry internships and the development of entrepreneurial skills through the Seed project. However, the music industry is not monolithic, and graduates need a range of skills to navigate it successfully; as Bridgstock (2009: 35) argues, graduates need to be able to "navigate the working world and successfully manage the career building process, based on attributes such as lifelong learning and adaptability". It is with this in mind that the BPM continues to evolve in alignment with the needs of both its cohort and the industry in which they will seek their success.

\section{Endnotes}

${ }^{1}$ At Griffith University (Queensland, Australia), students enroll to a degree program that is made up of a number of courses (subjects, modules or units of study).

\section{References}

Bennett, D. -

2007. Utopia for Music Performance Graduates: Is it Achievable, and How

Should it be Defined? British Journal of Music Education 24: 179-189.

2008. Portfolio Careers and the Conservatoire. In D. Bennett and M. Hannan

Eds. Inside, Outside, Downside Up: Conservatoire Training and Musicians'

Work. Perth: Black Swan Press: 61-72.

2009. Academy and the Real World: Developing Realistic Notions of Career in the Performing Arts. Arts and Humanities in Higher Education 8: 309-327.

Boud, D. 1995. Enhancing Learning Through Self Assessment. London: Kogan Page.

Bridgstock, R. -

2009. The Graduate Attributes We've Overlooked: Enhancing Graduate

Employability Through Career Management Skills. Higher Education

Research and Development 28: 31-44.

2013. Not a Dirty Word: Arts Entrepreneurship and Higher Education. Arts and Humanities in Higher Education 12: 122-137.

2014. The Graduate Attributes We've Overlooked: Enhancing Graduate

Employability Through Career Management Skills. Higher Education

Research and Development, 28 (1): 31-44.

doi: 10.1080/07294360802444347

Cloonan, M. 2005. What is Popular Music Studies? Some Observations. British Journal of Music Education 22: 77-93.

Folkestad, G. 2006. Formal and Informal Learning Situations or Practices vs Formal and Informal Ways of Learning. British Journal of Music Education 23: 135-145.

Frith, S. 2007. Live Music Matters. Scottish Music Review 1: 1-17.

Green, L. - 
2001. How Popular Musicians Learn: A Way Ahead for Music Education. Burlington: Ashgate.

2006. Popular Music Education in and for Itself, and for "Other" Music: Current

Research in the Classroom. International Journal of Music Education 24:

101-118.

2008. Music, Informal Learning and the School: A New Classroom Pedagogy. Aldershot and Burlington: Ashgate.

2010. Informal Learning in the Music Classroom: A Seven-Stage Program. IN J.

Ballantyne and B.L. Bartleet Eds. Navigating Music and Sound Education.

Newcastle upon Tyne: Cambridge Scholars Publishing: 96-114.

Holt, F. 2010. The Economy Of Live Music In The Digital Age. European Journal

Of Cultural Studies 13: 243-261.

Karubian, S. 2009. $360^{\circ}$ Deals: An Industry Reaction to the Devaluation of

Recorded Music. Southern California Interdisciplinary Law Journal 18: 395-462.

Kernfeld, B. D. 2002. The New Grove Dictionary of Jazz. ${ }^{\text {nd }}$ Edition. London:

Macmillan.

Lebler, D. -

2006. The Masterless Studio: An Autonomous Education Community. Journal of Learning Design 1: 41-50.

2007a. 3D Assessment: Looking Through a Learning Lens. In M. Hannan and D. Bennett Eds. New Models for Educating Professional Musicians in the Twenty-First Century. Proceedings of the 16th International Seminar of the Commission for the Education of the Professional Musician (CEPROM), 1014 July 2006, Hanoi National Conservatory of Music. Nedlands: International Society for Music Education (ISME): 195-208.

2007b. Student-as-Master? Reflections on a Learning Innovation in Popular Music Pedagogy. International Journal of Music Education 25: 205-221.

2008. Popular Music Pedagogy: Peer-Learning in Practice. Music Education Research 10: 193-213.

2010. Informal Learning in Formal Learning: Web 2 to the Rescue. In M. Hannan Ed. Musician in Creative and Educational Spaces of the 21st Century. Proceedings from the International Society for Music Education (ISME), 18th International Seminar of the Commission for the Education of the Professional Musician, 27-30 July 2010, Shanghai Conservatory of Music. Malvern: International Society for Music Education: 69-72.

2013. Using Formal Self- and Peer-Assessment as Proactive Tools in Building Collaborative Learning Environments: Theory into Practice. In H. Gaunt and $\mathrm{H}$. Westerlund Eds. Collaborative Learning in Higher Music Education: Why, What and How? Farnham: Ashgate: 111-122.

2015. The BoPMAT: Bachelor of Music Popular Music program. In D. Lebler, G. Carey and S. Harrison Eds. Assessment in Music Education: From Policy to Practice. London: Springer: 221-236.

D. Lebler, R. Burt-Perkins and G. Carey. 2009. What the Students Bring: Examining the Attributes of Commencing Conservatoire Students. International Journal of Music Education: Research 27: 232-249.

Marshall, L. 2013. The 360 Deal and the "New" Music Industry. European Journal of Cultural Studies 16: 77-99. 
Sadler, D. R. 2010. Assuring Academic Achievement Standards at Griffith University. http://app.griffith.edu.au/assessment-matters/pdfs/assuringacademic-achievement-standards-second-edition.pdf.

Accessed 10 February 2015.

Watson, A. and Forrest, D. 2012. Live Music and the Bands Culture in Victoria, Australia: An Exploratory Study of Education for the Professional Musician. In Educating Professional Musicians in a Global Context, 19th International Seminar of the Commission for the Education of the Professional Musician, Philippos Nakas Conservatory, Athens, Greece: International Society for Music Education: 104-111.

Westerlund, H. 2006. Garage Rock Bands: A Future Model for Developing Musical Expertise? International Journal of Music Education 24: 119-125. 